\title{
UPDATED INFECTION PREVENTION KIT
}

CODE, the Association for Dental Practice has published an updated version of its Infection Prevention Kit - a collection of practical tools which distil the new guidance and break it down into sections to make compliance with all aspects of cross infection control, sterilisation and decontamination manageable.

The Kit now contains the revised requirements of the November issue of the decontamination guidance HTM 01-05 from the Department of Health and takes into account the new DH/IPS audit tool for monitoring infection control compliance within dental practices.

It also includes a Charter on Patient Safety to reassure patients how seriously dentists take infection prevention and control at their practices, which can be exhibited in the reception area. Members can also add a link from their websites to the patient information video and charter on the CODE website.

The Kit is provided free to CODE

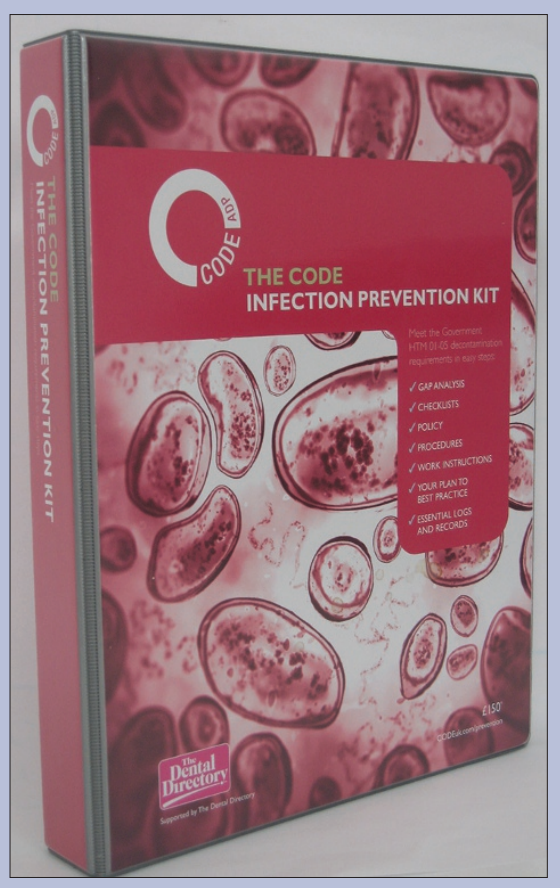

members and is available to non-members for $£ 150$.

Reader response number 58

\section{ALTERNATIVE TO MANUAL SCRUBBING}

Manufacturers of infection control products Schülke provide a wide range of products designed to offer solutions to your every hygiene requirement. These include gigasept enzymatic, a unique three-enzyme cleaner and disinfectant. A safe and efficient product, gigasept enzymatic offers an alternative to

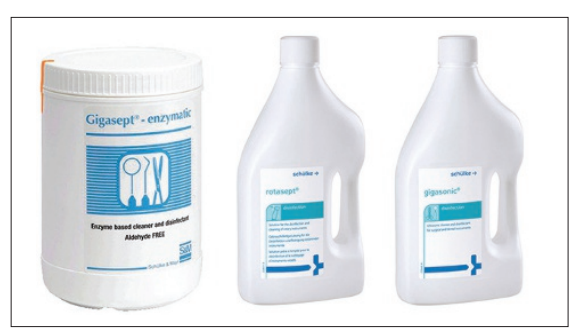

\section{FOAMING ACTION FORMULA}

Klin-Up Ultra is an alcohol free high level anti-microbial hand sanitiser for the safe and frequent disinfection of the hands following routine hand washing and is also suitable for use in situations where soap and water is manual scrubbing of instruments prior to autoclaving, and is effective against bacteria, fungi and viruses.

Rotasept is a ready-to-use solution for the cleaning and disinfection of rotary instruments, including burs, cutters, grinders, finishers and polishers. The product can be used in a static bath, or for quicker results inserted into an ultrasonic bath, while gigasonic is a clear liquid cleaning product designed for use in ultrasonic baths. Gigasonic ensures optimum appearance of instruments and prevents rusting and residue build up with just a five minute contact time.

Reader response number 59

not readily available. The unique non drip no waste 'foaming action formula' allows for complete coverage using the minimum of product.

Used as directed, a single application of Klin-Up can destroy $99.9 \%$ of all common pathogens present on the hands.

Reader response number 60 